\title{
Justification(reasons) of the use of film biopoclips in the injury of the vision organ
}

\author{
Niyazova Zebiniso Anvarovna, Abzalova Shakhnoza Rustamovna, \\ Buzrukov Batir Tulkunovich.
}

Tashkent Pediatric Medical Institute, Republic of Uzbekistan

\section{Email address:}

abzalova71@mail.ru (Abzalova Shakhnoza Rustamovna)

To cite this article:

Niyazova Zebiniso Anvarovna, Abzalova Shakhnoza Rustamovna, Buzrukov Batir Tulkunovich. Justification(reasons) of the use of film biopoclips in the injury of the vision Journal of research in health science.Vol. 2, No. 2, 2017, pp. 41-47. DOI 10.26739/2523-1243

\section{http://dx.doi.org/10.26739/2523-1243/-2017-2-2-7}

\begin{abstract}
Most of the recorded eye injuries are due to the high sensitivity of the eyes, even to the lightest, superficial injuries. Relative defenselessness of the visual organ due to the superficial location of eyeballs, along with the constant need for functioning in many activities, make it very vulnerable in the conditions of the catastrophe.
\end{abstract}

Keywords: trauma to the organ of vision, blindness, structure, complications, biomaterials.

\section{Обоснование использования пленочного биопокрытия при травмах органа зрения}

Аннотация: Большая часть регистрируемых травм органа зрения объясняется высокой чувствительностью глаз даже к самым легким, поверхностным повреждениям. Относительная беззащитность органа зрения в силу поверхностного расположения глазных яблок наряду с постоянной потребностью функционирования при многих видах деятельности делают его весьма уязвимым в условиях катастрофы.

Ключевые слова: травма органа зрения, слепота, структура, осложнения, биоматериалы. 
Niyazova Zebiniso Anvarovna, Abzalova Shakhnoza Rustamovna, Buzrukov Batir Tulkunovich. Justification(reasons) of the use of film biopoclips in the injury of the vision organ.

Травмы, в том числе и травмы органов зрения, занимают одно из ведущих мест в структуре заболеваемости населения Республики Узбекистан. Несмотря на громадное и все растущее их число, их общее число в мире неизвестно. Многие травмы, особенно легкие и среднетяжелые, не регистрируются. Пострадавшие не обращаются в медицинские учреждения, прибегают к самолечению [13].

Травмы органа зрения и их последствия до сих пор остаются одной из основных причин слепоты, слабовидения травмированного глаза и профессиональной инвалидности [5;18;8;21].

Тупые травмы, или контузии, составляют около $20 \%$ видов повреждения глаза. В отличие от проникающих ранений глаза, которые чаще возникают на производстве, тупые травмы нередко наблюдаются в быту [7].

Травма органа зрения является одной из серьезнейших медикосоциальных проблем. Особую актуальность она приобретает в связи с тем, что исходы повреждений глаз по-прежнему остаются основной причиной выхода на инвалидность по зрению [4;11].

Причем наибольший процент инвалидов по зрению $(65,5-70,6)$ приходится на лиц молодого, наиболее трудоспособного возраста от 20 до 45 лет [2].

Несмотря на очень малые размеры глаза (всего около 0,15\% общей поверхности человеческого тела), повреждения его составляют около 29 $\%$ общего травматизма [5].

Более 30 \% тяжелых травм глаз, приводящих к слепоте и инвалидности, составляют тупые травмы. Они отличаются большим разнообразием, часто приводят к таким серьезным осложнениям, как вторичная глаукома, вывихи и подвывихи хрусталика, гемофтальм, отслойка сетчатки, субатрофия и атрофия глазного яблока [17].

Учитывая то обстоятельство, что большую часть больных с этими травмами составляют люди трудоспособного возраста, можно говорить о важном социальном значении данной проблемы.

Структура современных травм органа зрения достаточно сложна. Рассмотрение их особенностей целесообразно начинать с механических повреждений, поскольку в количественном отношении они превалируют над вызванными этиологическими факторами.

Травматическое повреждение тканей глаза зависит от двух основных факторов: силы и направления удара, а также от особенностей анатомической структуры глаза. Патологические изменения, возникающие при тупой травме, складываются из двух компонентов: непосредственного повреждения тканей в момент удара и реактивных, воспалительных и дегенеративных процессов, развивающихся затем вследствие сложного комплекса причин, среди которых наибольшее значение имеет нарушение нормального кровообращения. Первичные травматические изменения различных тканей и отделов глазного яблока объясняются резким сплющиванием корнеосклеральной капсулы и прогибом ее внутрь глаза в момент травмы [8]. 
Большая часть регистрируемых травм органа зрения объясняется высокой чувствительностью глаз даже к самым легким, поверхностным повреждениям. Относительная беззащитность органа зрения в силу поверхностного расположения глазных яблок наряду с постоянной потребностью функционирования при многих видах деятельности делают его весьма уязвимым в условиях катастрофы. В случае множественной травмы при отсутствии повреждения, непосредственно угрожающего жизни раненого, повреждения глаз, грозящее потерей зрения, должно признаваться ведущим, так как из всех видов инвалидности слепота является наиболее тягостной [9].

Поскольку глазное яблоко является, по существу, замкнутой сферой с жидким и гелеобразным содержимым, тяжелые ушибы глаза часто сопровождаются разрывами склеры и роговицы, разрывающимися по механизму гидродинамического удара [4].

Характер повреждений связан с особенностями анатомического строения глазного яблока, длительными протекающими воспалительными и иммунными процессами во внутренних его оболочках.

Исходы тяжелых ранений органа зрения могут наступать в отдаленные сроки от 6 до 12 месяцев после повреждения.

В Андижанской области РУз проникающие ранения глазного яблока составляют $42,5 \%$, контузии глазного яблока $-23,9 \%$ и рваные раны век-14,3\%. Проникающие ранения глаза, являясь превалирующим видом поражений органа зрения в общей структуре глазного травматизма, чаще отмечаются у лиц мужского пола. Рваные раны век и разрушения глазного яблока чаще регистрировались у лиц женского пола в возрасте 18-30 и 31-45 лет [12].

По литературным данным повреждения глазного яблока и его вспомогательного аппарата в структуре детской глазной патологии составляют $10 \%$. Повреждения глаза у детей носят характер микротравм в 60\% случаев, тупые травмы в 30\%, проникающие ранения в $2 \%$ случаев. Из всех больных с тупыми травмами дети с повреждениями органа зрения составляют $70 \%$, с ожогами - $20 \%$ и с ранениями $-10 \%$. $70 \%$ ранений и ожогов и $85 \%$ тупых травм наблюдается у детей школьного возраста. У детей до 2 лет повреждения глаз носят исключительно спорадический характер. Среди больных с травмами мальчики составляют 85\%, девочки-15\% [1]. Наибольшее число травм органа зрения бывает в марте-апреле и сентябре-октябре в связи с изменениями погодных условий (весна и начало осени). Дети в это время очень активны в играх и частота повреждений глаза значительно увеличивается. Повреждающими предметами соответственно времени года являются снежки, хоккейные клюшки, шайбы, палки, камни и металлические или другие предметы, выпущенные из рогатки. Ожоги вызываются в основном карбидом кальция, кристаллами марганца, кислотами, химическим карандашом, канцелярским клеем, а также серой [1].

В работах А.П. Удянской (2008) показана актуальность проблемы 
Niyazova Zebiniso Anvarovna, Abzalova Shakhnoza Rustamovna, Buzrukov Batir Tulkunovich. Justification(reasons) of the use of film biopoclips in the injury of the vision organ.

травматизма глаза, дано научное обоснование диагностических критериев определения степени тяжести тупой травмы органа зрения, основанное на результатах комплексного судебно-медицинского и клинического исследований. По данным автора более 30 \% тяжелых травм глаз, приводящих к слепоте и инвалидности, составляют тупые травмы. Они отличаются большим разнообразием, часто приводят к таким серьезным осложнениям, как вторичная глаукома, вывихи и подвывихи хрусталика, гемофтальм, отслойка сетчатки, субатрофия и атрофия глазного яблока. Одно из наиболее часто встречающихся осложнений механической травмы глаза это кровоизлияние в переднюю камеру (гифема).

Механизм травмы органа зрения это контузия, проникающее ранение, осколочная травма, ожоги. Характером травмы являются непроникающие и проникающие повреждения . Клиническая картина травмы органа зрения полиморфна: возможно повреждение как одной оболочки глаза, так и нескольких, а иногда и всех структур, что приводит к гибели глаза. Тупые травмы, или контузии, составляют около $20 \%$ видов повреждения глаза. В отличие от проникающих ранений глаза, которые чаще возникают на производстве, тупые травмы нередко наблюдаются в быту.

В общей структуре поражений глаз у лиц женского пола превалируют рванные раны век, зарегистрированные в возрасте 18-30 лет и 31-45 лет. Термический ожог, составившей в структуре травматических поражений органа зрения $1,47 \%$, зарегистрирован только у одной женщины $(11,1 \%)$ старше 45 лет. Химический ожог отмечен у 3-х $(4,41 \%)$ человек [9].

В $27 \%$ случаев повреждения органа зрения сопровождает травма трех, четырех и более анатомических областей, что создает трудности при определении хирургической тактики у таких пострадавших. Синдром взаимного отягощения повреждений различных анатомических областей, многообразие, тяжесть и быстрота развития патологического процесса затрудняют диагностику сочетанной травмы глаза, в результате чего многие пострадавшие в связи с необходимостью оказания им медицинской помощи по жизненным показаниям , получают специализированную офтальмологическую помощь не сразу, а спустя несколько дней и даже недель, что ведет к утрате зрения пострадавшими. Лечение в таких случаях чаще всего оказывается бесперспективным, в результате чего растет инвалидность по зрению.

Поздняя диагностика глазной патологии в сочетанных травмах отмечена более чем в $50 \%$ случаев. Оказание медицинской помощи и лечения пораженных с повреждениями органа зрения при сочетанных травмах является одной из наиболее актуальных задач офтальмологии [1].

Проникающая травма глаза встречается ежегодно у 200 тысяч человек, $60 \%$ из которых теряют остроту зрения вследствие развития пролиферативной ретинопатии. Величина и локализация проникающего ранения во многом определяют развитие и тяжесть 
осложнений, определяющих исход травмы, частоту удаления глазного яблока, которое колеблется от 6,5 до $26,3 \%$ случаев. Решающее значение в профилактике развития тяжелых осложнений механической травмы глаза имеют диагностика и квалифицированная первичная хирургическая обработка, которые не всегда выполняются на должном уровне [3, 6, 10, 16,19].

K наиболее частым осложнениям проникающих ранений глаза относят травматическую катаракту (65\%), эндофтальмит $(30 \%)$, развитие инфекции (10\%). Применение системных антибиотиков малоэффективно в таких случаях. Исследователями также отмечено, что чаще в воспалительный процесс вовлекается экзогенная микрофлора. Риск развития осложнений напрямую связан со временем от получения травмы до госпитализации. Так, оптимальным "временным окном" для оказания медицинской специализированной помощи при проникающих повреждениях глаз определяется интервал в 12 часов. (D. Smith, K. Wrenn et al, 2002; Y Zhang, M.N. Zhang, 2017). Идеальным изделием могло бы послужить некоторое пленочное покрытие, которое бы прикладывалось на поврежденную склеру для барьерной функции и дальнейшей адекватной терапии. Данный имплантат должен обладать адекватной площадью покрытия, адгезивными свойствами, биосовместимым, с низкой частотой осложнений, не должен вызывать системные и побочные действия, быть простым в применении, экономически доступным [14;20].
Многие существующие имплантаты препятствуют прорастанию фибробластов и вызывают ответную хроническую реакцию воспаления тканей глаза. (A.W. Lloyd et al. 2001).

Биоматериалы для офтальмологии остаются одной из самых сложных и актуальных задач современной офтальмологии и имплантологии. Трудности заключаются в низкой биодоступности в виду особенностей анатомии и физиологии глаза: относительная низкая проницаемость эпителиальной мембраны роговицы, динамика слезной жидкости, назолакримальный дренаж и др. (Сао F et al. 2011). За последние десятилетия в дополнение к традиционным офтальмологическим препаратам (гели, мази, водные суспензии) были разработаны офтальмологические пленки, коллоидные системы, состоящие из нано-, микрочастиц, наноэмульсии, наносуспензии. [15].

По сравнению с традиционной субконъюктивальной инъекцией, пленочные покрытия демонстрируют более длительное воздействие, высокую биодоступность для оболочек глаза [15].

Биодеградируемые офтальмологические пленки на основе водорастворимых полимеров используются в качестве доставочных систем. Пленочные покрытия могут быть использованы как для системного, так и для местного применения. По сравнению с традиционными средствами, офтальмологические пленки обладают следующими преимуществами: увеличенное время контакта, биодоступность, возможность пролонгировать высвобождение 
Niyazova Zebiniso Anvarovna, Abzalova Shakhnoza Rustamovna, Buzrukov Batir Tulkunovich. Justification(reasons) of the use of film biopoclips in the injury of the vision organ.

лекарственного средства, буферная эффективность, снижение системных побочных эффектов. Полная биодеградация пленок обуславливает отсутствие необходимости удалять избыточное количество средства с зоны применения (Karatas A, Bakara T. 2001).

В литературе имеется большое количество публикаций, посвященных изучению частоты и распространенности различного рода офтальмологических заболеваний, встречающихся среди населения различных возрастов (Махкамова Ш.Г., 1999; Бобоев С.А.,2001; Маматхужаева Г.Н. 2004; Умаров Г.Т.,2004; Ниязметов Б.К.,2004; Аллаеров К.Б., 2004; Сусайкова М.С., 2005 и др.). Однако эти исследования в основном посвящены клиническим аспектам и профилактике того или иного отдельно взятого заболевания глаз. Нужно отметить, что в нашей республике практически не проводились работы, посвященные степени, структуре, распространенности глазного травматизма среди всего населения, инвалидности от них и их профилактике. Главными ориентирами при планировании и осуществлении профилактической работы являются эпидемиологические особенности глазного травматизма, клинико-статистические показатели, знание основных характеристик и состояние организации профилактики последнего. Анализ современной зарубежной литературы показал, что на сегодняшний день не существует пленочных покрытий в офтальмологии с барьерными свойствами для применения при проникающих ранениях глаза. Существующие имплантаты нацелены на длительное высвобождение лекарственных средств и повышение биодоступности препаратов. Нет данных о проведении морфологических исследований с целью сравнения традиционного метода оказания первичной хирургической обработки с наложением биоразлагаемых покрытий, не имеется исследований, посвященных изучению частоты и структуры офтальмологического травматизма, выявлению особых факторов, обуславливающих его тяжесть, не проводились исследования с целью оценки эффективности применения биопленок при открытой травме глаза в эксперименте и клинике(22).

Все выше приведенные данные свидетельствуют об актуальности исследования повреждений глаз и необходимости проведения нового исследования для решения данной проблемы.

\section{References/Использованная литература}

[1] Anina E.I., Krasvidi TA, Martoplyas K. V. Eye damage in the Ukrainian population // Tez. doc. X siezd ophthalmol. Ukraine.- Odessa, 2002.- P. 231-232 / Анина Е. И., Красновид Т.А., Мартопляс К. В. Повреждения глаз у населения Украины // Тез. докл. Х сьезда офтальмол. Украины.Одесса, 2002.- С. 231-232.

[2] Батурина Н. А. Оптимизация офтальмологической помощи сотрудникам Министерства внутренних дел России в локальном вооруженном конфликте: диссертация канд. Мед. наук.Москва, 2008.-147 с. 
[3] Бельченко В.А. Реконструкция верхней и средней зон лица у больных с травматическими деформациями и дефектами лицевого скелета с использованием аутотрансплантатов мембранного происхождения и металлоконструкция из титана: Автореф. дис. $\square$ д-ра мед. наук. - М., 1996. - 35 c.

[4] Волков В.В. Судебно-медицинская экспертиза травмы глаза // Судебно-медицинская экспертиза. 2010. №6 с.-42,43.

[5] Голубев С.Ю. Клинические критерии оценки степени вреда здоровью при повреждении органа зрения. Методические рекомендации. М.2001.

[6] Гундарова Р.А. Успешная помощь при травме глаз. I этап реабилитации. Методические рекомендации. - Москва, 2000.

[7] Гундорова Р. А., Степанов Д. В. Клинические особенности контузии глазного яблока с гипотоническим синдромом // Офтальмохирургия. 2003. - № 3. С. 6-9.

[8] Гундорова Р. А., Нероев В. В., Кашников В. В. Травмы глаза. - М.: ГЕОТАР-Медиа, 2009.-

[9] Жаров В.В., Клевно, В.А. Григорьева Е.Н. Судебно-медицинские критерии определения степени тяжести вреда здоровью при переломах скуловой костей// Судебно-медицинская экспертиза 2010. - №2. с. 10-12.

[10] Житенов В.М., Кочергин С.А., Крючкова Е.А., Мошетова П.К. Принципы оказания неотложной офтальмологической помощи пострадавшим в экстремальных ситуациях в мегаполисе // Русский медицинский журнал. - Москва, 2004. - Т.5. - № 3. - С. 69-73.

[11] Клевно В.А., Григорьева Е.Н. Судебно-медицинская оценка тяжести вреда здоровью в случае перелома скулоорбитального комплекса, осложненного офтальмологическими нарушениями // Судебно-медицинская экспертиза 2011. - № 3. С. 13-18. ].

[12] Курбанова Н.Ф. Социальные аспекты офтальмологического травматизма. // Тер арх. 2003. - № 3. C.12-16.

[13] Лисицин Ю.Г. Общественное здоровье и здравоохранение. - Москва, 2002. - 516 с.

[14] Baino, F., Perero, S., Ferraris, S., Miola, M., Balagna, C., Vern?, E., $\square$ Ferraris, M. (2014). Biomaterials for orbital implants and ocular prostheses: Overview and future prospects. Acta Biomaterialia. https://doi.org/10.1016/j.actbio.2013.12.014.

[15] El-Sousi, S., N?cher, A., Mura, C., Catal?n-Latorre, A., Merino, V., Merino-Sanju?n, M., \& D?ez-Sales, O. (2013). Hydroxypropylmethylcellulose films for the ophthalmic delivery of diclofenac sodium. Journal of Pharmacy and Pharmacology, 65(2), 193-200. https://doi.org/10.1111/ j.2042-7158.2012.01587.x

[16] Immonen I., Budde W.M., Knorr H.L. A simple and inexpensive system for the removal of silicone oil trough a 20 - gauge openins // Retina. - 1995. - Vol.15. - № 3. - P. 263-264.

[17] Jiang YR, Tao Y, Jonas JB. Traumatic choriodialysis treated by intraocular fibrin glue. Acta Ophthalmol. - 2010 Jun; 88 (4): e129-30.

[18] Karsterer P.A., Yunker C. Recognition and management of an orbital blowout fracture in an amateur boxer // J.of orthopaedic and sport physical therapy. - 2006. - V. 36. - № 8. - P. 610-616.

[19] Leewerenz M., Kochler T. Rehabilitation inder Schweiz - Dtsch. Angestel vers. - 2001. -№ 8. - P. 191-199.].

[20] Sun, S., Li, J., Li, X., Lan, B., Zhou, S., Meng, Y., \& Cheng, L. (2016). Episcleral drug film for better-targeted ocular drug delivery and controlled release using multilayered polycaprolactone (PCL). Acta Biomaterialia, 37, 143-154. https://doi.org/10.1016/j.actbio.2016.04.014).

[21] Trivellato P. F. A retrospective study of zygomatico-orbital complex and / or zygomatic arch fractures over a 71-month period // Dental traumatology. - 2011. - Vol. 27. - P. 135-142.).

[22] Niyazova Z.A.,Buzrukov B.T.,Salahiddinov K.Z.,Abzalova Sh.R. Use of biofilms in ophthalmology //European science review-2017 July-August № 7-8.-P.52-54. 